\title{
The Chemokine SDF1/CXCL12: A Novel Autocrine/Paracrine Factor Involved In Pituitary Adenoma Development
}

\author{
Federica Barbieri, Adriana Bajetto, Alessandra Pattarozzi, Monica Gatti, Roberto Würth, Carola \\ Porcile, Stefano Thellung, Alessandro Corsaro, Valentina Villa, Mario Nizzari and Tullio Florio*
}

Section of Pharmacology, Department of Oncology Biology and Genetics, University of Genova, Genova, Italy

\begin{abstract}
The relevance of the chemokine/chemokine receptor system has broaden to several tissues. Besides their physiologic role as chemotactic cytokines in immune surveillance, it is now clear that chemokines are key players in several pathological processes such as inflammation, infection, and cancer. In particular the altered expression of SDF1/CXCL12 and its receptor CXCR4 strongly affects cancer cell proliferation, recruitment of immunosuppressive cells, neovascularization and metastasization. CXCL12 and CXCR4 are widely expressed in central nervous system cells including hypotalamus and pituitary gland. Increasing evidence supports now the hypothesis that CXCL12 acts as a neuromodulatory activity on the hypothalamus/pituitary axis and is a regulatory molecule of pituitary function. Moreover, the differential expression of CXCL12 and CXCR4 in normal and tumor pituitary adenoma cells suggests their involvement in pituitary tumor development through autocrine/paracrine mechanisms leading to adenoma cell proliferation and hormone hypersecretion. Future studies focusing the pathways sustained by chemokines may help identify the tumor-initiating events and accordingly possible strategies may be developed targeting these pathways in human pituitary tumors.
\end{abstract}

Keywords: CXCL12, CXCR4, CXCR7, pituitary, pituitary adenoma.

\section{INTRODUCTION}

Chemokines are, low molecular weight proteins that, released by several different cell types, bind to a large family of seven transmembrane $\mathrm{G}$ protein-coupled cell surface receptors. These peptides were originally believed to exclusively belong to the immune system, although, over the time, they have emerged as pleiotropic, widely diffused class of regulatory peptides $[1,2]$.

The physiological role of chemokines was firstly identified in leukocyte trafficking, but subsequent convincing evidence demonstrates that chemokines are released in most tissues and chemokine receptors are expressed not only on leukocytes, but on a wide range of cell types, reflecting the broad spectrum of their local and systemic activities. It is now manifest that chemokine/chemokine receptor interaction plays a fundamental role in development, infection, wound healing, and tissue homeostasis [1]. Recently, the possibility has been raised that they might act as true neurotransmitters or neuromodulators in the central nervous system (CNS) [3]. Moreover, the expression of chemokines and chemokine receptors are often strongly up-regulated during tumorigenesis, affecting angiogenesis and angiostatic processes, tumor progression and metastasization [4].

Interestingly, the localizaton of chemokine receptors nearby or on the same cells as their ligands could account for

*Address correspondence to this author at the Department Oncology, Biology and Genetics - University of Genova, Viale Benedetto XV, 2, 16132 Genova, Italy; Tel/Fax: +39-010-3538806;

E-mail: tullio.florio@unige.it the strong local activity of these molecules that might be regulated by autocrine/paracrine mechanisms. Among chemokines, stromal cell-derived factor-1 (SDF1/CXCL12), which binds to CXCR4 and CXCR7 receptors, has been frequently involved in development, progression, survival, invasion, homing to metastatic sites and angiogenesis of various cancer types.

Over the past years, studies have increasingly shown the potential role of chemokines and, in particular, of SDF1/CXCR4 network, in the regulation at different levels of physiological or tumoral endocrine functions accounting novel biological role to this chemokine [5]. Therefore, this review will provide an update on chemokine/chemokine receptors control on pituitary cells function in normal pituitary physiology and adenoma development as autocrine/paracrine mediators/regulators of tumor progression/growth, and alterations in the tumor microenvironment.

\section{STRUCTURE AND CLASSIFICATION OF CHEMOKINES AND CHEMOKINE RECEPTORS}

To date, chemokine network includes approximately 20 receptors and 50 human ligands. Chemokines, a family of proinflammatory chemotactic cytokines, are small (8-10 $\mathrm{kDa}$ ), secreted peptides, that, accordingly to the number and spacing of two cysteine residues in the $\mathrm{NH}_{2}$-terminus, have been subdivided into four groups, named CXC (also called $\alpha$ chemokines, and named CXCL1-17), CC (or $\beta$ chemokines, CCL1-28), XC ( $\gamma$ chemokines, XCL1-2) and CX3C ( $\delta$ chemokines, CX3CL1) [2, 6, 7]. In CXC chemokine family, these cysteines are separated by a single amino acid, while in CC family the first two cysteines are adjacent [8]. XC group is represented by just two chemokines (XCL1/lymphotactin 
$\alpha$ and XCL2/lymphotactin $\beta$ ) containing only two of the four conserved cysteines found in the other subfamilies [8]. Finally, CX3C family includes only one member, called CX3CL1/fractalkine (and its murine homologue neurotactin), in which the first two cysteines are separated by three amino acids. This molecule is peculiar since it exists in both soluble and membrane-bound forms [9].

According to the presence of the conserved tripeptide motif glutamic acid-leucine-arginine (ELR) at the $\mathrm{N}$ terminus of the protein, before the CXC domain, CXC chemokines are further classified in ELR+ or ELR-. Chemokine with the ELR sequence have been found to chemoattract and activate neutrophils. Chemokine without the ELR motif appear to control monocytes, T-cells, NK cells, B-lymphocytes, basophils and eosinophils chemotaxis. Notably, different members of CXC chemokine family play opposite roles in the regulation of angiogenesis; members containing the ELR motif such as CXCL1, -2, -3, -5, -6, -7, 8 are directly chemotactic for endothelial cells and can stimulate angiogenesis in vivo, whereas members lacking the ELR motif are interferon $\gamma$-inducible (CXCL9, -10 and -11) and act as potent inhibitors of angiogenesis $[10,11]$.

In general, all chemokine subfamilies show some common features: pleiotropism, promiscuity and redundancy. Chemokines exert their biological activity through the interaction with heterotrimeric, seventransmembrane $G$ protein-coupled receptors (GPCRs), classified on the basis of the chemokine group to which their ligand(s) belongs, i.e. CXCR (7 receptors), CCR (from CCR1 to CCR11), CX3CR1 (a single receptor for CX3CL1) and XCR1 (for XCL1-2). Moreover, there are two chemokines, CXCL7 and CXCL14 belonging to the CXC subfamily and CCL18, of the CC family, for which a specific receptor has not been unanimously identified, yet [7]. Some chemokine receptors bind a single chemokine, whereas others display promiscuous binding of different ligands [2].

The assumption that CXCL12 act through the unique interaction with $\mathrm{CXCR} 4$, was recently challenged, since it was shown that this chemokine can also bind to an orphan receptor (Receptor Dog cDNA 1, RDC1) [12] that was subsequently renamed CXCR7 [13]. Furthermore, CXCR7 is also a receptor for CXCL11/I-TAC (Interferon-inducible Tcell chemoattractant) [14], a chemokine interacting also with CXCR3 receptor. Thus, chemokine network represents a highly complex, fine-tuned regulatory system.

Interestingly, it has been reported that several chemokine receptors (CCR2, CCR5, CXCR1, CXCR2, CXCR4 and CXCR7) can homo- or hetero-dimerize as consequence of the ligand binding [15-18], a process that was proposed to be required for the modulation of the signal transduction of these receptors.

Upon chemokine binding, a conformational change of the receptors occurs that activate heterotrimeric $G$ proteins: the $\mathrm{G} \alpha$ subunit exchanges GDP for GTP and dissociates from the $\beta \gamma$ subunit and from the receptor leading to intracellular transduction of the signal [19]. Most of the involved G proteins belong to the Gi/Go, pertussis toxin (PTX) sensitive subfamily, leading to the modulation of classical second messenger systems such as adenylyl cyclase (AC)-cAMP, phospholipase C (PLC)/inositol tris-phosphate (IP3)- $\mathrm{Ca}^{2+}$ / diacyl glycerol-PKC. However, the phosphatidyl inositol 3 kinase-Akt, the MAP kinase ERK1/2 and the focal adhesion kinase (FAK, Pyk2, etc) systems also represent key messengers in chemokine activity.

Within the $G$ protein complex (Gi/Go), the $\beta \gamma$ subunit seems to play a major role, rather than the $\alpha$ subunit. For instance, the stimulation of cell migration, that can be very relevant in several physiological and pathological activities of chemokines, appears to require the functional coupling of the receptor to Gai, as migration is completely inhibited by treatment with PTX [20], even though the Gai itself may not be necessary for cell migration [21]. Indeed, the $\beta \gamma$ subunits of the G-protein carries the bulk of the signal of chemokine receptors out, and, in particular, it was observed that only the $\beta \gamma$ subunits released from Gi-coupled receptors, but not those released by the Gs- or Gq-coupled receptors, can mediate cell migration.

\section{THE CXCL12/CXCR4-CXCR7 CHEMOKINERGIC SYSTEM}

Chemokine stromal cell-derived factor 1 (SDF1), hereafter designated as CXCL12, accordingly to the systematic taxonomy of chemokines [7], belongs to the CXC subfamily. It was originally cloned from bone marrow cell supernatants and characterized as a pre-B-cell stimulatory factor. CXCL12 is a highly conserved chemokine (99\% homology between mouse and man), supporting the relevance of its biological role, and includes three alternative splicing variants of CXCL12 (named $\alpha, \beta$ and $\gamma$ ), mainly divergent in the C-terminus of the peptide [22]. The two main splice forms, CXCL12- $\alpha$ and CXCL12- $\beta$, are identical in the first 89 amino acid sequences, but CXCL12- $\beta$ has 4 additional amino acids at the C-terminus [23]. The first 17 amino acids, crucial for the binding ability of CXCL12 to CXCR4 [24, 25], are identical in both isoforms, but CXCL12- $\alpha$ is more sensitive to proteolysis by serum CD26/dipeptidyl peptidase than CXCL12 $\beta$ [26], implying different functions or regulatory roles in vivo.

CXCL12 is a chemotactic factor for T cell, monocytes, pre-B-cells, dendritic cells and hematopoietic progenitor cells and supports B-cell progenitor and CD $34^{+}$cell proliferation $[27,28]$. However, its expression is not restricted to immune cells, but CXCL12 mRNA and protein were also identified within the CNS in neurons, astrocytes, microglia and endothelia [29, 30]. CXCL12- $\alpha$ is the most abundant isoform in the brain [22], being localized in specific neuronal structures such as cingulated gyrus and CXCL12- $\beta$ extensively expressed in cerebral endothelial cells [31].

CXCL12 exerts most of its effects via the binding to CXCR4 since the transductional role of CXCR7 is still controversial, and the current opinion is that CXCR7 may act as decoy receptor to modulate the concentration of the chemokine at target tissues [14].

The interplay between CXCL12 and CXCR4 is critical for the normal development since the deletion of CXCL12 and CXCR4 genes in mice, causes a similar embryological lethal phenotype, leading to deficient bone marrow myeloid cell formation and severe defects in cardiovascular and neuronal development [32, 33]. Similarly to CXCL12, also CXCR4 is expressed in several tissues outside the immune system, including endothelial cells, embryonic germinal neu- 
roepithelium and mature neurons, astrocytes and microglia $[34,35]$. Moreover, CXCR4 was reported to represent a coreceptor for the entry of T-lymphotropic of the immunodeficiency virus (HIV-1) into CD4-positive T cells [36].

CXCR4, composed of 352 amino acids, belongs to the seven transmembrane helices GPCR family. CXCL12 binds to CXCR4 extracellular and transmembrane regions, being the latter critical for G-protein signaling. CXCL12 interaction with CXCR4 first triggers receptor dimerization and activates multiple intracellular signalling pathways mediated by $\mathrm{Gi} / \mathrm{Go}$ proteins, including $\mathrm{G} \alpha$ (sensitive to Bordetella pertussis toxin, PTX) and G $\beta \gamma$-mediated signals. $\mathrm{G} \alpha \iota$ induces the inhibition of adenylyl cyclase (AC) activity, thereby reducing the cytosolic concentration of cyclic AMP (cAMP), and inhibiting protein kinase A (PKA) activity. Gaq trasduces CXCR4 signals through the activation of phospholipase C $\beta$ (PLC $\beta$ ) which increases inositol-1,4,5trisphosphate (IP3) levels and transient elevation of intracellular calcium concentration. Chemokine stimulation of G $\beta \gamma$ subunits directly activates phosphoinositide 3-kinase (PI-3K), a survival regulator acting on effectors of apotosis [37], to induce Akt activation. This pathway is mainly involved, although nort exclusively, in the chemotactic response to CXCL12.

Importantly, chemokines in general, and CXCL12 in particular, are also poweful activators of the MAP kinase cascade and in particular the pathway involving ERK1/2 as well as the phosphorylation of focal adhesion kinase (FAK) and protein tyrosine kinase 2 (PTK 2) [38, 39].

Chemokines may stimulate the Ras-Raf-ERK1/2 MAP kinase pathway, without the involvement of $G$ proteins [29, 35]. An alternative signaling was proposed, although not definitely established, identifying a role for PI-3K in ERK1/2 activation in light of the reduced activity of these MAP kinases after treatment with wortmannin or LY294002 (specific PI-3K inhibitors). This observation was confirmed in mice lacking PI-3K $\gamma$ subunit $[40,41]$. Mutational studies showed that the third intracellular loop of CXCR4 is responsible for the $\mathrm{G}$ protein binding and ERK1/2 activation. However, the chemotactic activity of the receptor requires not only the intracellular signaling via this portion of the receptor but also the second intracellular loop and the carboxyl-terminus, suggesting that this important biological response requires a complex array of signals [42].

Recently, several studies proposed that CXCR4dependent activation of ERK1/2 was mediated by transactivation of tyrosine kinase receptors. Cross-talk between growth factor and $G$ protein-coupled receptors is now believed to play an important role both in normal and tumoral responses. In particular, the transactivation of members of the epidermal growth factor receptor (EGFR) family and their downstream signaling pathways is critical for the mitogenic activity of different GPCR ligands, including chemokines. CXCL12-induced CXCR4 activation in breast and ovarian cancer cells causes EGFR and/or HER2/neu phosphorylation through $G$ protein-dependent activation of cytosolic tyrosine kinases of the Src family [4345]. Thus a cross-talk between chemokine and growth factor signaling pathways was demonstrated. Recently, CXCR4 and EGFR variant (EGFRvIII) cross-talk was involved in breast cancer cell invasion as a result of enhanced CXCR4 expression through transcriptional and post-translational mechanisms [46]. CXCL12-CXCR4 axis was also shown to activate JNK/SAPK signaling [47] that seems to contribute to CXCL12-mediated cell invasion. CXCR4 signaling involves JAK/STAT pathway activation through a dimerization-dependent, PTX-independent mechanism [48]. CXCL12 binding to CXCR4 causes the rapid tyrosine phosphorylation of the receptor in a JAK kinase dependent fashion, as demonstrated by the rapid recruitment of several members of the JAK family (JAK1, JAK2, JAK3 or TYK2) that mediates CXCL12-induced $\mathrm{Ca}^{++}$mobilization [48]. However, the activation of this pathway seems to occur only in specific cell types as hematopoietic progenitors and $\mathrm{T}$ cells [49] and it was demonstrated to be dispensable for CXCL12-induced chemotaxis [50]. In fact, JAK2 and JAK3 deficient cells, as well as HEK293 cells engineered to overexpress dominant negative forms of JAK2 and JAK3, showed no changes in CXCL12-induced $\mathrm{Ca}^{++}$fluxes or chemotaxis [50].

Compelling evidence has emerged that protein-tyrosine phosphatases (PTPs) are also involved in the modulation of CXCR4 signaling. In particular, the Src homologycontaining protein-tyrosine phosphatase 1 (SHP1), but also the SH2 domain-containing inositol 5-phosphatases (SHIP), acts as negative regulators of chemokine signaling, while the ubiquitously expressed PTP, SHP2, constitutively associated with CXCR4, appears to enhance chemokine signaling [51, 52]. Different roles for these phosphatases were identified: CXCL12 stimulation of $\mathrm{T}$ cells enhanced the tyrosinephosphorylation and activity of SHP2 [51], while CXCL12induced chemotaxis, actin polymerization and ERK1/2 activation were enhanced in $\mathrm{T}$ and $\mathrm{B}$ cells and macrophages, derived from SHP1 deficient mice, as well as chemotaxis, actin polymerization and $\mathrm{Ca}^{++}$influx were enhanced in response to CXCL12 in both immature and mature hematopoietic cells derived from SHIP-deficient mice [53], suggesting a negative role for these phosphatases in CXCR4 intracellular signaling.

CXCL12 also binds to CXCR7, sharing this receptor with the chemokine family member CXCL11. Since the identification of CXCR7 as a new receptor for CXCXL12, the role of CXCL12 in regulating diverse biological processes appeared more complex. CXCR7 has been described both as a signaling and a non-signaling receptor depending on the cell type and tissue expression, which, in turn, determines the biological function of this receptor. Most chemokine receptors contain the "DRYLAIV" sequence, which is crucial for coupling to Gai [54] and induction of $\mathrm{Ca}++$ fluxes [55]. This motif is slightly modified in CXCR7 [56], possibly preventing its interaction with Gai-proteins (CXCR7 sensitivity to PTX is still controversial) and the activation of classical intracellular signaling commonly associated to chemokine receptor (for example increase in intracellular $\mathrm{Ca}^{++}$concentration) [57]. From this evidence it was proposed that CXCR7 was a sort of decoy receptor able to modulate CXCL12 concentrations in the microenvironment to attenuate its biological effects [58]. In lymphocytes CXCL12 (or CXCL11) binding induces CXCR7 internalization [13] providing evidence of receptor activation, and increasing evidence suggests that signal transduction activated by CXCL12/CXCR7 binding may occur through phosphorylation of MAPK [57] and Akt [59]. 
Thus, recent studies proposed CXCR7 also as a signaling receptor in several normal and tumor cell types [59].

Still several reports support the role of CXCR7 as a decoy receptor or as "molecular sink" for CXCL12 [54] playing a role in the regulation of ligand levels and creating a gradient for cell migration.

Furthermore, the biological response mediated by CXCL12 binding to CXCR4 or CXCR7 may be regulated by different factors as the pattern of receptor expression (CXCR7 seems to be mostly present in cancer and embryonic cells, [14]), the possible competitive binding of CXCL11 and the influence of CXCL12 tissue concentration.

\section{CXCL12/CXCR4 AS AUTOCRINE/PARACRINE NETWORK IN CANCER}

Chemokines and their receptors play critical roles in several steps of tumor development, growth, progression and dissemination [60]. Cancer cells express a variety of chemokine receptors and release multiple chemokines [61]. The concomitant expression of growth factor receptor-ligand pair in the same cells was previously described as an autocrine/paracrine mechanism of cancer cell stimulation, resulting in clinical aggressive behavior and faster growth of several tumor histotypes [62, 63]. The expression of functional CXCR4 has been widely reported in several solid human cancers as breast cancer cells [64], prostate [65], melanoma [66], small cell lung cancer [67] and glioblastoma [37, 68]. Moreover, several leukemic and lymphoma cells [69] express CXCR4 on cell surface.

Cancer cells take advantage of the expression of chemokines and their receptors to modulate the immune response to the tumor, induce tumor angiogenesis and growth, alter the microenvironment, and facilitate metastasis spreading to specific target organs [70]. Several studies showed that CXCR4 is the most widely expressed chemokine receptor in human malignancies and its activation by CXCL12 causes proliferation, migration, invasion and metastasization and promotes neo-angiogenesis [71, 72].

In vitro studies showed that CXCL12 is a growth factor for glioblastoma cells increasing their proliferation and migration likely through an autocrine/paracrine mechanism and that CXCL12-dependent proliferation is correlated to the phosphorylation of both ERK1/2 and Akt and that these kinases are independently involved in glioblastoma cell proliferation [37].

In addition, it has been reported that CXCL12 stimulates chemotaxis, survival and proliferation in glioblastoma and medulloblastoma primary cell cultures and xenografted tumors $[72,73]$.

The simultaneous expression of CXCR4 and its ligand and their mitogenic activity suggesting a pivotal autocrine/paracrine activity of this receptor-ligand pair, have been also demonstrated in other human brain tumor types, such as meningiomas. The signaling mechanisms activated by CXCL12 via CXCR4 in primary cultures from meningioma cells showed that CXCR4 significantly increased of DNA synthesis through a marked phosphorylation/activation of ERK1/2 [74].
In addition, the magnitude of CXCL12-induced cell proliferation was significantly correlated with the MIB1 proliferation index in the corresponding surgical specimen [74]. This observation further support the hypothesis of the occurrence of an autocrine/paracrine proliferative loop, in which tumor derived CXCL12 may provide a proliferative advantage for the cells sensitive to CXCL12 stimulation.

Similar mechanisms to promote tumor development have been also observed in other cancer histotypes such as breast carcinoma. CXCR4 overexpression was recognized as a requirement for breast cancer cell proliferation [75]. Silencing of CXCR4 causes a significant reduction of breast cancer cell proliferation in vivo and in vitro [76, 77], suggesting a possible autocrine/paracrine growth factor role of CXCL12 [78].

It is noteworthy that $17 \beta$-estradiol (E2)-induced proliferation of T47D and MCF-7 breast cancer cells is mediated by increased synthesis and release of CXCL12, identified as a novel estrogens-responsive gene that, in anautocrine/paracrine fashion, controls ERK $1 / 2$ activity [44, 79]. We investigated the role of CXCL12/CXCR4 axis as a convergence point between E2 and EGFR intracellular pathways in breast cancer cells and demonstrated that E2-induced proliferation requires the synthesis and secretion of CXCL12 and the autocrine activation of CXCR4 that, in turn, causes a cSrc-dependent transactivation of EGFR [44].

CXCR4 signaling is mainly dependent on ligand binding, but there is recent evidence that ligand-independent mechanisms can be activated in different tumor types. In glioblastomas, EGFR stimulation can induce CXCR4 phosphorylation to induce its transactivation [80]. The effects of the selective CXCR4 antagonist, AMD3100 observed in our previous study in SKBR3 breast cancer cells may support these findings. In fact, also in the absence of CXCL12, the CXCR4 antagonist significantly reduced cell proliferation, EGFR phosphorylation, and ERK1/2 activation. Thus, we can hypothesize that, in this cell line, a constitutive proliferative loop may occur in which HER2/neu ligand-independent activity may sustain a constitutive CXCR4 activation (as demonstrated by the effects of the selective inhibitor AMD3100 in untreated cells and, indirectly, by the low responsivity to exogenous CXCL12) that may control both EGFR and HER2/neu activation [44].

Interestingly, tumor promoting activity of CXCL12 can be exerted not only via a direct induction of cell proliferation. Accumulating data show that some chemokines, including CXCL12, may serve as tissue-specific attractant molecules, promoting tumor-cell migration. Among the chemokine receptors commonly expressed in cancer cells, CXCR4 and CCR7 represent the key receptors involved in metastasis of different cancers [64, 81]. Due to the widespread expression of CXCL12, the CXCL12/CXCR4 axis can direct metastatic CXCR4-expressing cells to bone marrow, liver, lung and other organs [82] while the CCL21/CCR7 axis has been shown to be involved in lymph node metastasization [83, 84].

Metastasization is a multistep process that include cell detachment from the primary tumor mass, migration into blood or lymphatic vessels, where tumor cells may receive a chemoattracting signal that make them to extravasate and 
enter the target tissue. Here, tumor clls are homed into the site of future metastatic growth [85]. In several human malignancies, CXCL12 chemoattracted CXCR4 positive tumor cells and regulated several aspects of their metastatic behavior. Small-cell lung cancer (SCLC), a tumor characterized by rapid progression and metastasization preferentially to bone marrow, highly express CXCR4 [86] and its activation enhances the migratory and invasive response, and adhesion to marrow stromal cells. CXCL12 pivotal role in the directional migration of cancer cells during the metastatic process was reported by several studies $[87,88]$. In fact, primary breast carcinomas are characterized by a distinctive pattern of metastases, which does not correlate with patterns of bloodflow, but suggests preferential homing, adhesion, survival, and proliferation in specific organs and tissues [78]. CXCL12 exhibits peak levels of expression in a variety of tissues representing the first destinations of cancer metastasis. In fact, in several other aggressive solid neoplasms CXCR4 directs the migration of cancer cells following CXCL12 concentration gradient: neuroblastoma [89, 90], colorectal cancer [91], brain cancers [68, 73] ovarian [92], prostate [87], renal cell [93] and oral squamous cell [94] carcinomas.

Generally, studies on the role played by chemokines in metastasis have been skewed more towards chemokine receptor expression than chemokine ligand production: the first report showed that CXCR4 positive breast cancer cells are responsive to CXCL12 [64] and was followed by the observation that CXCR4 is upregulated by VEGF in breast carcinoma making these cells responsive to CXCL12 [95]. CXCL12 enhances motility and adhesion of lung cancer cells [67] and breast cancer cells [91], and tumor metastasization of lymph nodes may reflect CXCL12 production by lymph node cells through the concentration gradient derived [96].

These observations were confirmed in studies in which antibodies-induced CXCL12 neutralization reduces NSLCC metastasis formation [97] and were in keeping with reports showing that low host plasma CXCL12 predicts distant metastases [98].

Reports of the role of CXCL12 as chemoattractant for CXCR4-expressing cancer cells toward metastasis sites, allowed the re-evaluation of the biological and clinical significance of the chemokine produced by tumor cells. In fact, the analysis of CXCR4 expression in a large series of human breast cancers demonstrated that CXCL12 expression but not CXCR4 is significantly associated with relapse-free and overall survival [99]. It was proposed that locally produced CXCL12 may saturate the receptor through an autocrine mechanism preventing chemotactic stimuli towards CXCL12-producing target organs. In addition, since CXCL12 is also expressed by tumor stromal fibroblast and endothelial cells it might also affect, via paracrine mechanisms, the sensitivity of breast cancer cells to chemotactic signals [99]. Similarly, DNA hypermethylation of CXCL12 promoter and the resultant down-regulation of CXCL12 expression in breast carcinomas were identified as mechanism of regulation of cancer metastasis [100]: cancer cells lacking CXCL12, but maintaining over-expression of CXCR4, can more frequently spread to target organs in which the ligand is highly secreted.
Similar results were obtained in several colonic cancer cell lines and primary carcinoma tissues lacking CXCL12 expression: the re-establishment of CXCL12 expression in these cells profoundly reduced metastatic tumor formation in vivo [101].

Thus, it was proposed that the silencing of the ligand arm of CXCL12/CXCR4 axis changes the homeostatic autocrine and paracrine signaling to a strictly endocrine communication arc that facilitates metastasis of colonic and breast carcinomas [101, 102].

In this view, a dual role for CXCL12 in tumor progression can be identified: the direct autocrine activation of CXCR4 by its ligand may provide, on one hand, a proliferation gain of function to tumor cells but, on the other, may prevent the metastatic diffusion. The latter point may result in a significant better prognosis especially for patients with high malignant tumors in which metastatic spread is one of the major clinical problems. Conversely, in less malignant, non-metastatic neoplasms (i.e. meningiomas) the expression of this chemokine within the tumor may provide a faster growth.

\section{AUTOCRINE/PARACRINE FUNCTIONS OF CHEMOKINE IN NORMAL PITUITARY}

The endocrine and neural systems share complex connections through molecules such as neuropeptides, neurotransmitters, and cytokines and chemokines. Cytokines, such as IL-1, IL-2, TNF $\alpha$. and. TGF $\beta$, act in an autocrine/paracrine manner in the pituitary, affecting hormone secretion and pituitary growth [103].

IL-1 $\beta$ whose receptor was detected within mouse adenohypophysis [104], inhibits prolactin (PRL) secretion from dispersed rat pituitary cells through the regulation of both cAMP production and agonist-induced $\mathrm{Ca}^{++}$fluxes [105107]. IL-1 $\beta$ mRNA was identified in rat anterior pituitary cells supporting an autocrine/paracrine regulation of pituitary function in situations in which stimulation of IL-1 secretion is induced, such as during infectious processes [108].

IL-6 receptors were also identified in human normal pituitary [109] as well as IL-6 secretion by normal rat pituitary cells [110]. The pituitary source of IL-6 was identified in the folliculostellate (FS) cells and IL-6 was proposed to promote an autocrine/paracrine loop for regulation of different pituitary hormones secretion [111], including adrenocorticotropic hormone (ACTH) [112] and PRL, luteinizing hormone (LH) and growth hormone $(\mathrm{GH})$ in normal rat pituitary cell cultures $[113,114]$ interfering with several intracellular mechanisms [115]. Interestingly IL-6 displays opposite effects in normal and tumoral pituitary cells by inhibiting the growth of normal anterior pituitary cells [116] and stimulating the proliferation in a paracrine manner of pituitary adenoma cells [111]. More recently, also IL-18 was proposed to exert paracrine effects in pig anterior pituitary being the ligand and its receptor expressed by different subsets of GH secreting pituitary cells [117]. However, altogether these studies did not provide solid bases for a physiological role of these cytokines in the regulation of pituitary function.

Pleiotropic chemokines were also identified as regulators of the hypothalamic-hypophyseal axis. In fact, the cytokine- 
induced neutrophil chemoattractant, CINC (the rat counterpart of the human growth-related oncogene, CXCL1/GRO) was reported to be expressed in the posterior pituitary, in the paraventricular nucleus (PVN) of the hypothalamus and the median eminence. In response to stressful stimuli, CINC expression is highly increased in the PVN and this chemokine is released in the median eminence [118] to reach its receptor (CXCR2) expressed in pituitary cells and induce the release of PRL and (slightly) GH, and to inhibit LH and FSH secretion [119].

CXCR2 expression was also identified in normal human pituitary, thus supporting the general relevance of this regulatory mechanism [120]. Importantly, a sustained CINC secretion was observed in a subpopulation of cultured pituitary [121] and FS cells [122]. Thus, an autocrine/paracrine intrapituitary regulation may occur via the secretion of CINC/GRO by pituitary cells that, in turn, may modulate the activity of CXCR2-expressing cells. However, also other chemokines may participate to the regulation of the hypothalamus-pituitary system in physiological and pathological conditions. For instance, another CXCR2 ligand, CXCL8 (IL-8), was identified in brain areas (PVN of the hypothalamus and hippocampus) involved in the hypothalamuspituitary-adrenal axis. Importantly, CXCL8 secretion is under the control of corticosteroids through a feed-back mechanism, thus supporting a physiological role for this molecule in the pituitary regulation of ACTH secretion [123].

However, among all chemokines, CXCL12 is now considered one of the major regulatory molecules of interconnection between immune and nervous systems, and the CXCL12/CXCR4 system was reported to play an important regulatory role in anterior pituitary function.

Initial studies identified binding sites for CXCL12 in rat pituitary, by means of autoradiographic experiments [124], and in hypothalamus, using immunohistochemistry [125]. In the latter study, co-expression of CXCL12 and CXCR4 was observed [125]. Thus, the concomitant expression of CXCL12 in hypothalamic neurons and CXCR4 at pituitary level, suggested that this chemokine could represent a novel hypothalamic factor possibly contributing to the regulation of anterior pituitary function.

Furthermore, co-expression of CXCL12 and CXCR4 was also recognized in rat pituitary explants by RT-PCR [126].

CXCL12 activation of CXCR4 leads to the proliferation of GH4C1 and GH3 rat pituitary adenoma cell, and GH secretion in $\mathrm{GH} 4 \mathrm{C} 1$ [126, 127], GH3 [128], and primary cultures of normal rat pituitary cells [128]. In normal rat pituitary, CXCR4 is completely localized within GH secreting cells and CXCL12 treatment stimulated GH gene transcription [128], reinforcing the role of the CXCL12/CXCR4 system as relevant player in the regulation of normal physiological function of somatotrophs.

In addition, immunohistochemical studies showed that rat anterior pituitary cells do not express CXCL12, which was confined to the posterior lobe, but only CXCR4 [128]. As a consequence the chemokinergic regulation of anterior pituitary cells should be controlled by external CXCL12 originating from hypothalamic neurons or systemic circulation via blood vessels [5].
Several transduction systems were reported to be activated by $\mathrm{CXCR} 4$ in rat pituitary cells.

In $\mathrm{GH} 4 \mathrm{C} 1$ cells, two intracellular pathways activated by CXCL12 that independently contribute to cell proliferation and GH secretion were described. Interestingly, it was shown that CXCL12-induced GH release was a solely dependent on an increase in intracellular $\mathrm{Ca}^{++}$concentration, while the regulation of $\mathrm{GH} 4 \mathrm{C} 1$ cell proliferation was dependent on both the $\mathrm{Ca}^{++}$-independent stimulation of the MAP kinase ERK1/2 activity (as also demonstrated in GH3 cells [128]) and the $\mathrm{Ca}^{++}$-dependent activation of the cytosolic tyrosine kinase Pyk2 and the large conductance, $\mathrm{Ca}^{++}$-dependent $\mathrm{K}^{+}$ channels, $\mathrm{BK}_{\mathrm{Ca}}[126,127]$. Importantly, the pharmacological inhibition of each of all these pathways completely reverted the proliferation induced by CXCL12, indicating that all these intracellular transducers $\left(\mathrm{Ca}^{++}, \mathrm{Pyk} 2, \mathrm{BK}_{\mathrm{Ca}}\right.$ and ERK1/2) are necessary for such an effect [126].

In addition, CXCL12 and CXCR4 are co-expressed in rat posterior pituitary cells and were reported to regulate vasopressin secretion [129].

Partially different results were obtained in normal human pituitary derived from autopsies. In a recent paper we showed by immunohistochemical analysis, a scattered expression of both CXCR4 and CXCL12 within the pituitary anterior lobe (Fig. 1A) [130]. In that study we reported a higher CXCR4 expression as compared with its ligand, since the receptor was detected in about $1 / 3$ of the anterior pituitary cells, while the expression of CXCL12 was confined to only $12 \%$ of the cells. The distribution of both CXCL12 and CXCR4 was not homogenous throughout the tissue, with large portions of the anterior pituitary completely negative for both the proteins, some areas where only few positive cells and rare zones with higher expression. Using double immunofluorescence and confocal microscopy analysis to identify the hormonal profile of the CXCR4 immunopositive cells, we showed that the expression of this chemokine receptor is not confined to a specific cell population $(\mathrm{GH}-$, PRL- or ACTH-secreting cells) but it was observed in subsets of all the different pituitary subpopulations. Staining pituitary sections with all the hormones together, few cells expressing CXCR4 were also identified that express neither $\mathrm{GH}$ and PRL nor ACTH [130]. Although further studies are required, this evidence suggests that CXCL12/CXCR4 system may also be expressed in undifferentiated/progenitor cells.

Conversely, the less frequent CXCL12-positive cells were mainly confined in ACTH-expressing pituitary cells, showing a lower percentage of co-localization with other hormone-secreting cells [130]. Interestingly, all the CXCL12-labeled cells were also CXCR4 positive, whereas several CXCR4-positive/CXCL12-negative cells were detected [130].

Importantly, no co-localization of either CXCR4 or CXCL12 was observed in endothelial cells (CD34 staining) in normal hypophysis and pituitary adenomas, and no expression of CXCR4 in FS cells (S100 staining) was detected in human normal pituitaries [130].

Thus, in normal pituitary subset of cells releasing CXCL12 are likely involved in the paracrine regulation of hormone secreting cells, that, accordingly to data obtained in 
Normal pituitary
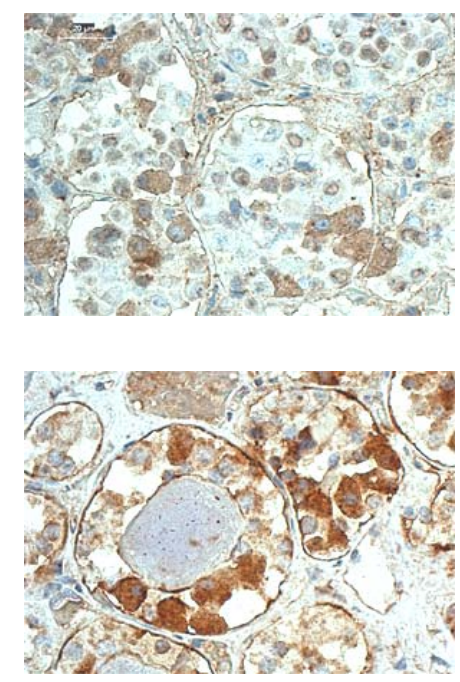

\section{Pituitary adenoma}

CXCL12

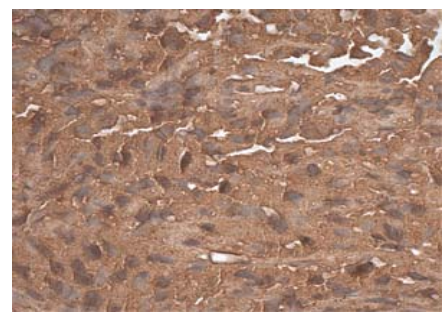

CXCR4

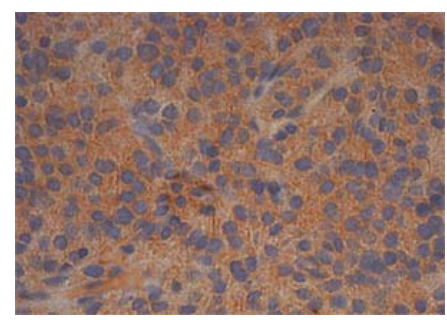

Fig. (1). Expression of CXCL12 and CXCR4 in normal and tumor pituitary gland.

A) Representative immunohistochemical experiments in normal anterior lobe from autoptic pituitary sections showed CXCL12 immunoreactivity in scattered cells throughout the tissue, with large negative areas, while CXCR4 is stronger expressed than the ligand although confined to subsets of cells in the pituitary acini; a discrete number of CXCR4-negative cells are also clearly observable.

B) The pattern of expression of CXCL12 and CXC4 in human GH-secreting pituitary adenoma histological sections, characterized by cellular monomorphism and lack of acinar organization, showed that all tumor cells are intensely and uniformly positive for both CXCL12 and its receptor, homogeneously distributed in the tissue.

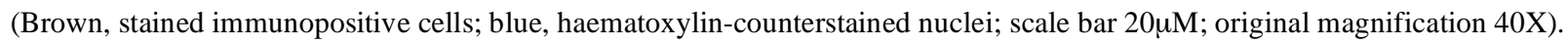

rat, may contribute to the modulation of the secretory activity, altogether with hypothalamic hormones. However, conditions leading to the disruption of the regulatory pathways activated by CXCL12/CXCR4 interaction might play a role in the development and/or progression of pituitary adenomas.

\section{BIOLOGICAL EFFECTS OF CXCL12 IN PITUITARY ADENOMA CELLS}

Pituitary adenomas are typically benign, slow-growing tumors that arise from cells in anterior pituitary gland, and account for approximately $15 \%$ of primary brain tumors. Local mass-related effects and/or hormone hypersecretion represent the main clinical signs associated with these tumors. Pituitary adenomas are classified according to their secretory pattern as prolactinomas (30\% of pituitary tumors), $\mathrm{GH}$ secreting (15\%) and ACTH-secreting (10\%) tumors. Pituitary adenomas producing biologically inactive hormones ( $\alpha$ subunit of TSH, LH and FSH, or the entire gonadotropins) or derived from "null cells" are defined as clinically non-functioning pituitary adenomas (NFPAs) and represent about $30 \%$ of the total pituitary tumors [131].

The understanding of intracellular mechanisms involved in the pathogenesis and progression of pituitary tumors is still incomplete. In the recent past years, important new information on the role of intrinsic pituitary genetic alterations, disordered growth factors, and signaling proteins involved in pituitary tumorigenesis has been reported.

However, very few studies addressed the potential role of any component of the chemokine family in regulating human pituitary tumorigenesis.
In particular, CXCR2, one of the CXCL8 receptors, was detected in high concentration in human pituitary adenomas [120], suggesting a possible participation of this chemokine in the development of pituitary tumors. CXCL8 mRNA was identified in pituitary by RT-PCR in all pituitary adenomas [132], but these homogeneous pattern of expression was not confirmed using in situ hybridisation in both normal anterior pituitary specimens and pituitary adenomas [133].

More recently, a number of studies addressed the expression of CXCL12 and/or CXCR4 in pituitary tumors suggesting the possibility that this chemokine may act as a promoting factor for adenoma development [130, 134, 135].

In this view, we analyzed the pattern of expression of CXCR4 and CXCL12 in a large series of surgical samples derived from pituitary adenomas (GHomas and NFPAs) by reverse transcription-PCR (RT-PCR), immunohistochemistry, and confocal immunofluorescence [130]. Almost all the GHomas analyzed $(25 / 27,92 \%)$ expressed CXCR4 mRNA and also CXCL12 was detected in the majority of the cases $(17 / 27,60 \%)$. Similar results were obtained in NFPAs in which CXCR4 mRNA was detected in $81 \%$ of the tumors (30/37) and CXCL12 in 78\% (29/37) (Fig. 2) [130]. Interestingly, the co-expression of ligand and receptor was largely the most common condition, strongly supporting an autocrine/paracrine regulation of tumor growth by this chemokine [130]. Immunohistochemical analysis on paraffin-embedded sections of both GHomas and NFPA showed that in the adenomas that express CXCL12 and CXCR4 both proteins are present in all tumor cells, in contrast to the scattered expression in human normal pituitary (Fig. 1B) [130]. Subsequent studies confirmed this results showing that high 


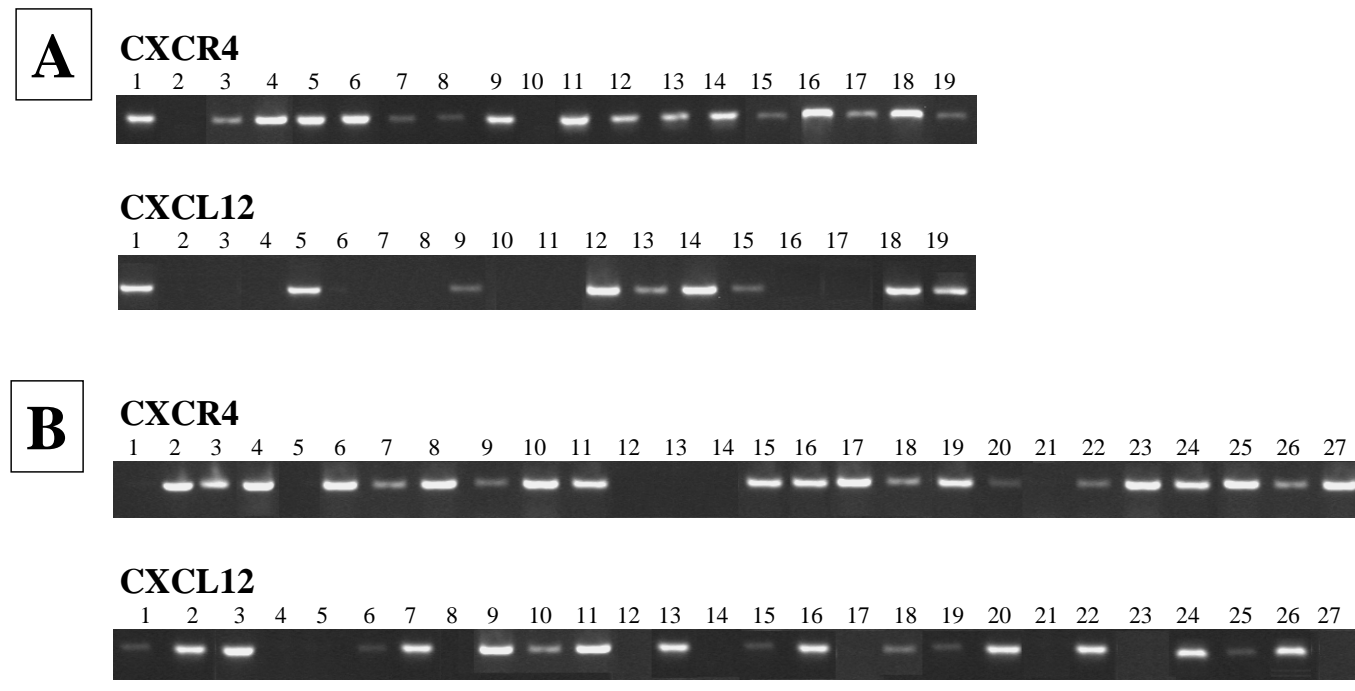

Fig. (2). CXCL12 and CXCR4 mRNA expression evaluated by RT-PCR in human pituitary adenoma specimens

RT-PCR evaluation in pituitary tumor samples demonstrates the presence of CXCL12 and CXCR4 mRNA in a high percentage of human GH-secreting adenomas (GHomas, A) and clinically non-functioning pituitary adenomas (NFPAs, B).

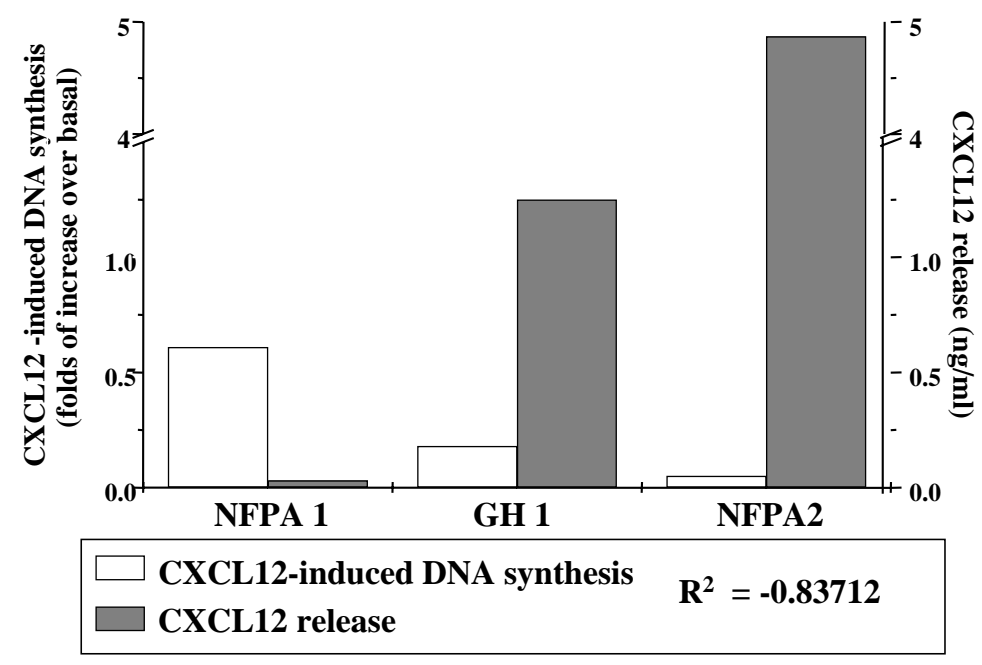

Fig. (3). Correlation between in vitro CXCL12 secretion and the proliferative response to CXCL12 in human pituitary adenoma primary cultures

CXCL12-induced DNA synthesis, analyzed by [ $\left.{ }^{3} \mathrm{H}\right]$-thymidine uptake, is significantly inversely correlated to the levels of CXCL12 secretion showed by each primary culture analyzed (two NFPAs and one GH-secreting adenoma) suggesting the presence of an autocrine proliferative loop that abolish the effects of the exogenously added chemokine. (Data are derived from [130]).

percentage of GHomas and NFPA have a diffuse expression of both CXCL12 and CXCR4 [134, 135]. One study also identified CXCL12 expression in PRL, ACTH and TSH secreting adenomas [135], confirming the general role of this chemokine in the regulation of pituitary adenoma development and/or progression. Interestingly, CXCL12 expression level was directly correlated with microvasculature densities within the adenomas, suggesting a regulatory role by hypoxia [135]. The concomitant up-regulation of CXCL12 and CXCR4 by hypoxia in GH3 pituitary adenoma cell line was reported to interact with classical endocrine pathways to upregulate $\mathrm{GH}$ production [138].

Finally, all the pituitary adenoma histotypes, as well as the AtT20 mouse corticotroph pituitary adenoma cell line, express also the second CXCL12 receptor, CXCR7 [136].
Such generalized CXCR4 and CXCL12 over-expression in human pituitary adenomas as compared to normal pituitary, strongly suggests that, in conditions of deregulation, this receptor system represents a relevant factor for pituitary adenoma development and/or progression. To address this issue, the effects of CXCL12 on cell proliferation were evaluated in vitro on a small number of fibroblast-free primary cultures [137] derived from GHomas, NFPA and ACTH-secreting adenomas. In this study [130], CXCL12 induced a statistically significant increase in DNA synthesis in the majority $(65 \%)$ of the adenoma tested. Interestingly, in few adenomas, the blockade of CXCR4 with AMD3100 caused, beside the abolishment of CXCL12 effects, a pronounced inhibition of basal DNA synthesis. Thus, it was hypothesized that a basal secretion of CXCL12 was maintained in vitro causing an autocrine constitutive stimulation 


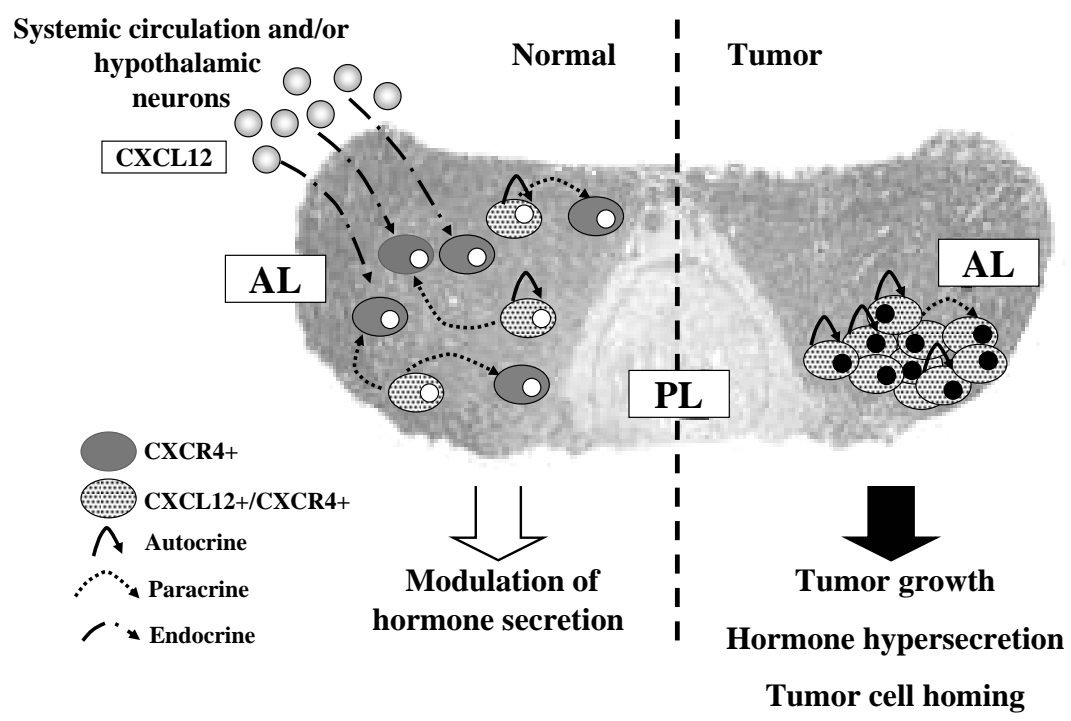

Fig. (4).Schematic overview of the CXCL12/CXCR4 axis in normal an adenomatous (rat) pituitary

In normal anterior lobe (AL) CXCL12, secreted by hypothalamic neurons and/or coming from the systemic circulation, may act as a novel hypophysiotrophic factor for CXCR4-expressing pituitary cells. Moreover, the presence of scattered CXCL12-CXCR4 co-expressing positive and CXCR4-positive cells an autocrine/paracrine stimulation of pituitary cell functions may occur (left part).

In the pituitary adenoma development process, CXCL12 is markedly produced by transformed anterior pituitary cells almost totally coexpressing the receptor and, in an autocrine/paracrine manner, may stimulate tumor cells to proliferate and to hyper-secrete specific hormones. This possibly also contributes to the maintenance of tumor cells in a microenvironment in which the high level of CXCL12 preferably promote cell homing than migration. These pathways may represent a promoting factor for pituitary local adenoma growth (right part).

of DNA synthesis. In fact, CXCL12 was secreted in vitro with a statistically significant inverse relationship with the proliferative response induced by exogenous CXCL12 (Fig. 3) [130]. Moreover, the existence of an autocrine regulation of CXCR4 activity was indirectly supported by the demonstration of the absence of CXCR4 activating mutations in 34 GHomas and 17 NFPAs [134].

Thus, all together these data suggest that pituitary adenoma cells over-express CXCL12 and CXCR4, as compared to normal tissue.

These evidences support the hypothesis that this chemokine may represent a novel growth factor for pituitary cells, acting either via endocrine (through the blood stream or released from hypothalamus) and/or autocrine/paracrine pathways. Importantly, the autocrine mechanisms seem to be maximally effective in pituitary adenomas rather than in normal hypophysis (Fig. 4). In fact, most of the CXCR4expressing normal pituitary cells do not express CXCL12 and the autocrine stimulation of CXCR4 seems to represent a key characteristic of pituitary adenomas [130].

Further studies will be needed to verify whether CXCL12 over-expression is causative for pituitary adenoma formation or only provides a selective proliferation advantage favouring clonal expansion of cells in which tumor-promoting mechanisms are already activated. Importantly, beside a role in tumor progression the autocrine activation of CXCR4 may also play a relevant role in maintenance of the tumors, due to its positive effects on cell survival.

The lack of progression from adenoma to carcinoma and metastasization in pituitary tumors is intriguing and still unclear.
Locally produced CXCL12 may act in a complex system in which it can cause alteration of the normal control of mitotic division, increasing growth and blocking differentiation, and apoptosis in a way similar to that observed in malignant tissues. However, as observed in several different tumor histotypes, this gain of function as far as proliferation is associated to high intratumor concentration of the chemokine that by the abrogation of CXCL12 gradient from distant sites might block metastatic dissemination.

\section{CONCLUSIONS}

In this review, we analyzed the potential role of chemokines, and in particular of CXCL12, as a novel pituitary growth factor. Although it is well recognized the role of several growth factors in pituitary adenoma development and of chemokines in the control of the proliferation of many different tumor histotypes, a possible chemokine regulation of pituitary function was addressed in a systematic way only in the very last years.

Several mechanisms by which CXCL12 can control pituitary function and stimulate pituitary adenoma cell proliferation can be hypothesized (schematically depicted in Fig. 4): (1) CXCL12, released by hypothalamic neurons, may act as a novel hypophysiotrophic factor. This regulation may occur either by influencing PVN neuronal cells to produce hypothalamic releasing hormones, that control anterior pituitary cells functions (hypothalamic neurons also express the CXCL12 receptor CXCR4), or by direct CXCL12 release by hypothalamic neurons that may reach, via the pituitary portal system, CXCR4-expressing pituitary cells; (2) CXCL12, coming from the systemic circulation can reach pituitary, enters into the capillary net of the anterior lobe of the pituitary gland and interacts with pituitary cells that express 
CXCR4; in our view these first two mechanisms are mainly effective in normal pituitary, where they act to modulate hormone secretion; (3) during pituitary adenoma development, CXCL12 production may be induced in anterior pituitary cells by still unidentified mechanisms and, through an autocrine/paracrine process stimulates adenohypophyseal tumor-initiated cells to proliferate and hypersecrete specific hormones.

In this view CXCL12 may represent a promoting factor for pituitary adenoma development. Alternatively, already transformed pituitary adenoma cells may start to secrete CXCL12 that confers increased proliferative activity and prolonged life-span to these cells contributing to the expansion of the adenomas.

These data are opening a very important new research area in the field of pituitary regulation that may lead to the identification of important new pharmacological targets (i.e. CXCR4) for innovative compounds (antagonists of CXCR4, such as AMD3100 or newer derivatives), able to improve the outcome of the pharmacological therapy of pituitary adenomas.

\section{REFERENCES}

[1] Bajetto A, Bonavia R, Barbero S, Florio T, Schettini G. Chemokines and their receptors in the central nervous system. Front Neuroendocrinol 2001; 22: 147-84.

[2] Zlotnik A, Yoshie O, Nomiyama H. The chemokine and chemokine receptor superfamilies and their molecular evolution. Genome Biol 2006; 7: 243.

[3] Rostene W, Kitabgi P, Parsadaniantz SM. Chemokines: a new class of neuromodulator? Nat Rev Neurosci 2007; 8: 895-903.

[4] Vandercappellen J, Van Damme J, Struyf S. The role of CXC chemokines and their receptors in cancer. Cancer Lett 2008; 267 : 226-44.

[5] Barbieri F, Bajetto A, Porcile C, Pattarozzi A, Schettini G, Florio T. Role of stromal cell-derived factor 1 (SDF1/CXCL12) in regulating anterior pituitary function. J Mol Endocrinol 2007; 38: 383-9.

[6] Allen SJ, Crown SE, Handel TM. Chemokine: receptor structure, interactions, and antagonism. Annu Rev Immunol 2007; 25: 787820 .

[7] Zlotnik A, Yoshie O. Chemokines: a new classification system and their role in immunity. Immunity. 2000; 12: 121-7.

[8] Rollins BJ. Chemokines Blood 1997; 90: 909-28.

[9] Bazan JF, Bacon KB, Hardiman G, et al. A new class of membrane-bound chemokine with a CX3C motif. Nature 1997; 385: 640-4.

[10] Li M, Ransohoff RM. The roles of chemokine CXCL12 in embryonic and brain tumor angiogenesis. Semin Cancer Biol 2009; 19: 111-5.

[11] Strieter RM, Belperio JA, Phillips RJ, Keane MP. CXC chemokines in angiogenesis of cancer. Semin Cancer Biol 2004; 14: 195-200.

[12] Heesen M, Berman MA, Charest A, Housman D, Gerard C, Dorf ME. Cloning and chromosomal mapping of an orphan chemokine receptor: mouse RDC1. Immunogenetics 1998; 47: 364-70.

[13] Balabanian K, Lagane B, Infantino S, et al. The chemokine SDF$1 / \mathrm{CXCL} 12$ binds to and signals through the orphan receptor RDC1 in T lymphocytes. J Biol Chem 2005; 280: 35760-6.

[14] Burns JM, Summers BC, Wang Y, et al. A novel chemokine receptor for SDF-1 and I-TAC involved in cell survival, cell adhesion, and tumor development. J Exp Med 2006; 203: 2201-13.

[15] Levoye A, Balabanian K, Baleux F, Bachelerie F, Lagane B. CXCR7 heterodimerizes with CXCR4 and regulates CXCL12mediated G protein signaling. Blood 2009;113:6085-93.

[16] Mellado M, Rodriguez-Frade JM, Manes S, Martinez AC. Chemokine signaling and functional responses: the role of receptor dimerization and TK pathway activation. Annu Rev Immunol 2001; 19: 397-421.
[17] Percherancier Y, Berchiche YA, Slight I, et al. Bioluminescence resonance energy transfer reveals ligand-induced conformational changes in CXCR4 homo- and heterodimers. J Biol Chem 2005; 280: 9895-903.

[18] Rodriguez-Frade JM, Vila-Coro AJ, de Ana AM, Albar JP, Martinez AC, Mellado M. The chemokine monocyte chemoattractant protein-1 induces functional responses through dimerization of its receptor CCR2. Proc Natl Acad Sci U S A 1999; 96: 3628-33.

[19] O'Hayre M, Salanga CL, Handel TM, Allen SJ. Chemokines and cancer: migration, intracellular signalling and intercellular communication in the microenvironment. Biochem J 2008; 409: 635-49.

[20] Neptune ER, Bourne HR. Receptors induce chemotaxis by releasing the betagamma subunit of $\mathrm{Gi}$, not by activating $\mathrm{Gq}$ or Gs. Proc Natl Acad Sci U S A 1997; 94: 14489-94.

[21] Neptune ER, Iiri T, Bourne HR. Galphai is not required for chemotaxis mediated by Gi-coupled receptors. J Biol Chem 1999; 274: 2824-8.

[22] Nagasawa T, Kikutani H, Kishimoto T. Molecular cloning and structure of a pre-B-cell growth-stimulating factor. Proc Natl Acad Sci U S A 1994; 91: 2305-9.

[23] Shirozu M, Nakano T, Inazawa J, et al. Structure and chromosomal localization of the human stromal cell-derived factor 1 (SDF1) gene. Genomics 1995; 28: 495-500.

[24] Doranz BJ, Orsini MJ, Turner JD, et al. Identification of CXCR4 domains that support coreceptor and chemokine receptor functions. J Virol 1999; 73: 2752-61.

[25] Loetscher P, Gong JH, Dewald B, Baggiolini M, Clark-Lewis I. Nterminal peptides of stromal cell-derived factor-1 with CXC chemokine receptor 4 agonist and antagonist activities. J Biol Chem 1998; 273: 22279-83.

[26] De La Luz Sierra M, Yang F, Narazaki M, et al. Differential processing of stromal-derived factor-1alpha and stromal-derived factor-1beta explains functional diversity. Blood 2004; 103: 24529.

[27] Christopherson K, 2nd, Hromas R. Chemokine regulation of normal and pathologic immune responses. Stem Cells 2001;19: 388-96.

[28] Luster AD. Chemokines--chemotactic cytokines that mediate inflammation. N Engl J Med. 1998; 338: 436-45.

[29] Bajetto A, Bonavia R, Barbero S, Florio T, Costa A, Schettini G. Expression of chemokine receptors in the rat brain. Ann N Y Acad Sci 1999; 876: 201-9.

[30] Ohtani Y, Minami M, Kawaguchi N, et al. Expression of stromal cell-derived factor-1 and CXCR4 chemokine receptor mRNAs in cultured rat glial and neuronal cells. Neurosci Lett 1998; 249: 1636.

[31] Stumm RK, Rummel J, Junker V, et al. A dual role for the SDF$1 / \mathrm{CXCR} 4$ chemokine receptor system in adult brain: isoformselective regulation of SDF-1 expression modulates CXCR4dependent neuronal plasticity and cerebral leukocyte recruitment after focal ischemia. J Neurosci 2002; 22: 5865-78.

[32] Nagasawa T, Hirota S, Tachibana K, et al. Defects of B-cell lymphopoiesis and bone-marrow myelopoiesis in mice lacking the CXC chemokine PBSF/SDF-1. Nature 1996; 382: 635-8.

[33] Zou YR, Kottmann AH, Kuroda M, Taniuchi I, Littman DR. Function of the chemokine receptor CXCR4 in haematopoiesis and in cerebellar development. Nature 1998; 393: 595-9.

[34] Bajetto A, Bonavia R, Barbero S, et al. Glial and neuronal cells express functional chemokine receptor CXCR4 and its natural ligand stromal cell-derived factor 1. J Neurochem 1999; 73: 234857.

[35] Oh JW, Drabik K, Kutsch O, Choi C, Tousson A, Benveniste EN CXC chemokine receptor 4 expression and function in human astroglioma cells. J Immunol. 2001; 166: 2695-704.

[36] Feng Y, Broder CC, Kennedy PE, Berger EA. HIV-1 entry cofactor: functional cDNA cloning of a seven-transmembrane, $\mathrm{G}$ protein-coupled receptor. Science 1996; 272: 872-7.

[37] Barbero S, Bonavia R, Bajetto A, et al. Stromal cell-derived factor 1alpha stimulates human glioblastoma cell growth through the activation of both extracellular signal-regulated kinases $1 / 2$ and Akt. Cancer Res 2003; 63: 1969-74.

[38] Bajetto A, Barbero S, Bonavia R, et al. Stromal cell-derived factor1alpha induces astrocyte proliferation through the activation of 
extracellular signal-regulated kinases $1 / 2$ pathway. J Neurochem 2001; 77: 1226-36.

[39] Tilton B, Ho L, Oberlin E, et al. Signal transduction by CXC chemokine receptor 4 . Stromal cell-derived factor 1 stimulates prolonged protein kinase $\mathrm{B}$ and extracellular signal-regulated kinase 2 activation in T lymphocytes. J Exp Med 2000; 192: 31324.

[40] Abi-Younes S, Sauty A, Mach F, Sukhova GK, Libby P, Luster AD. The stromal cell-derived factor-1 chemokine is a potent platelet agonist highly expressed in atherosclerotic plaques. Circ Res 2000; 86: 131-8.

[41] Sasaki T, Irie-Sasaki J, Jones RG, et al. Function of PI3Kgamma in thymocyte development, $\mathrm{T}$ cell activation, and neutrophil migration. Science 2000; 287: 1040-6.

[42] Roland J, Murphy BJ, Ahr B, et al. Role of the intracellular domains of CXCR4 in SDF-1-mediated signaling. Blood 2003; 101: 399-406.

[43] Cabioglu N, Summy J, Miller C, et al. CXCL-12/stromal cellderived factor-1alpha transactivates HER2-neu in breast cancer cells by a novel pathway involving Src kinase activation. Cancer Res 2005; 65: 6493-7.

[44] Pattarozzi A, Gatti M, Barbieri F, et al. 17beta-estradiol promotes breast cancer cell proliferation-inducing stromal cell-derived factor-1-mediated epidermal growth factor receptor transactivation: reversal by gefitinib pretreatment. Mol Pharmacol 2008; 73: 191202.

[45] Porcile C, Bajetto A, Barbieri F, et al. Stromal cell-derived factor1alpha (SDF-1alpha/CXCL12) stimulates ovarian cancer cell growth through the EGF receptor transactivation. Exp Cell Res 2005; 308: 241-53.

[46] Rahimi M, George J, Tang C. EGFR variant-mediated invasion by enhanced CXCR4 expression through transcriptional and posttranslational mechanisms. Int J Cancer 2009.

[47] Brand S, Dambacher J, Beigel F, et al. CXCR4 and CXCL12 are inversely expressed in colorectal cancer cells and modulate cancer cell migration, invasion and MMP-9 activation. Exp Cell Res 2005; 310: 117-30.

[48] Vila-Coro AJ, Rodriguez-Frade JM, Martin De Ana A, MorenoOrtiz MC, Martinez AC, Mellado M. The chemokine SDF-1alpha triggers CXCR4 receptor dimerization and activates the JAK/STAT pathway. Faseb J 1999; 13: 1699-710.

[49] Zhang XF, Wang JF, Matczak E, Proper JA, Groopman JE. Janus kinase 2 is involved in stromal cell-derived factor-1alpha-induced tyrosine phosphorylation of focal adhesion proteins and migration of hematopoietic progenitor cells. Blood 2001; 97: 3342-8.

[50] Moriguchi M, Hissong BD, Gadina M, et al. CXCL12 signaling is independent of Jak2 and Jak3. J Biol Chem 2005; 280: 17408-14.

[51] Chernock RD, Cherla RP, Ganju RK. SHP2 and cbl participate in alpha-chemokine receptor CXCR4-mediated signaling pathways. Blood 2001; 97: 608-15.

[52] Wain CM, Westwick J, Ward SG. Heterologous regulation of chemokine receptor signaling by the lipid phosphatase SHIP in lymphocytes. Cell Signal 2005; 17: 1194-202.

[53] Kim CH, Hangoc G, Cooper S, et al. Altered responsiveness to chemokines due to targeted disruption of SHIP. J Clin Invest. 1999; 104: 1751-9.

[54] Haraldsen G, Rot A. Coy decoy with a new ploy: interceptor controls the levels of homeostatic chemokines. Eur J Immunol 2006; 36: 1659-61.

[55] Sierro F, Biben C, Martinez-Munoz L, et al. Disrupted cardiac development but normal hematopoiesis in mice deficient in the second CXCL12/SDF-1 receptor, CXCR7. Proc Natl Acad Sci U S A. 2007; 104: 14759-64. Epub 2007 Sep 5.

[56] Thelen M, Thelen S. CXCR7, CXCR4 and CXCL12: an eccentric trio? J Neuroimmunol 2008; 198: 9-13. Epub 2008 Jun 3.

[57] Hartmann TN, Grabovsky V, Pasvolsky R, et al. A crosstalk between intracellular CXCR7 and CXCR4 involved in rapid CXCL12-triggered integrin activation but not in chemokinetriggered motility of human $\mathrm{T}$ lymphocytes and CD34+ cells. J Leukoc Biol 2008; 84: 1130-40.

[58] Mahabaleshwar H, Boldajipour B, Raz E. Killing the messenger: The role of CXCR7 in regulating primordial germ cell migration. Cell Adh Migr 2008; 2: 69-70.

[59] Wang J, Shiozawa Y, Wang Y, et al. The role of CXCR7/RDC1 as a chemokine receptor for CXCL12/SDF-1 in prostate cancer. J Biol Chem 2008; 283: 4283-94.
[60] Burger JA, Kipps TJ. CXCR4: a key receptor in the crosstalk between tumor cells and their microenvironment. Blood 2006; 107: 1761-7.

[61] Raman D, Baugher PJ, Thu YM, Richmond A. Role of chemokines in tumor growth. Cancer Lett. 2007; 256: 137-65. Epub 2007 Jul 12 .

[62] Kang H, Watkins G, Parr C, Douglas-Jones A, Mansel RE, Jiang WG. Stromal cell derived factor-1: its influence on invasiveness and migration of breast cancer cells in vitro, and its association with prognosis and survival in human breast cancer. Breast Cancer Res 2005; 7: R402-10.

[63] Rempel SA, Dudas S, Ge S, Gutierrez JA. Identification and localization of the cytokine SDF1 and its receptor, CXC chemokine receptor 4 , to regions of necrosis and angiogenesis in human glioblastoma. Clin Cancer Res 2000; 6: 102-11.

[64] Muller A, Homey B, Soto H, et al. Involvement of chemokine receptors in breast cancer metastasis. Nature 2001; 410: 50-6.

[65] Sun YX, Wang J, Shelburne CE, et al. Expression of CXCR4 and CXCL12 (SDF-1) in human prostate cancers (PCa) in vivo. J Cell Biochem 2003; 89: 462-73.

[66] Robledo MM, Bartolome RA, Longo N, Rodriguez-Frade JM, Mellado M, Longo I, van Muijen GN, Sanchez-Mateos P, Teixido J. Expression of functional chemokine receptors CXCR3 and CXCR4 on human melanoma cells. J Biol Chem 2001; 276: 45098105.

[67] Kijima T, Maulik G, Ma PC, et al. Regulation of cellular proliferation, cytoskeletal function, and signal transduction through CXCR4 and c-Kit in small cell lung cancer cells. Cancer Res 2002; 62: 6304-11.

[68] Zhou Y, Larsen PH, Hao C, Yong VW. CXCR4 is a major chemokine receptor on glioma cells and mediates their survival. J Biol Chem 2002; 277: 49481-7.

[69] Bertolini F, Dell'Agnola C, Mancuso P, et al. CXCR4 neutralization, a novel therapeutic approach for non-Hodgkin's lymphoma. Cancer Res 2002; 62: 3106-12.

[70] Thelen M, Stein JV. How chemokines invite leukocytes to dance. Nat Immunol 2008; 9: 953-9.

[71] Balkwill F. The significance of cancer cell expression of the chemokine receptor CXCR4. Semin Cancer Biol 2004; 14: 171-9.

[72] Bajetto A, Barbieri F, Dorcaratto A, et al. Expression of CXC chemokine receptors 1-5 and their ligands in human glioma tissues: role of CXCR4 and SDF1 in glioma cell proliferation and migration. Neurochem Int 2006; 49: 423-32.

[73] Rubin JB, Kung AL, Klein RS, et al. A small-molecule antagonist of CXCR4 inhibits intracranial growth of primary brain tumors. Proc Natl Acad Sci U S A 2003; 100: 13513-8.

[74] Bajetto A, Barbieri F, Pattarozzi A, et al. CXCR4 and SDF1 expression in human meningiomas: a proliferative role in tumoral meningothelial cells in vitro. Neuro-oncol 2007; 9: 3-11.

[75] Li YM, Pan Y, Wei Y, et al. Upregulation of CXCR4 is essential for HER2-mediated tumor metastasis. Cancer Cell 2004; 6: 459-69.

[76] Lapteva N, Yang AG, Sanders DE, Strube RW, Chen SY. CXCR4 knockdown by small interfering RNA abrogates breast tumor growth in vivo. Cancer Gene Ther 2005; 12: 84-9.

[77] Smith MC, Luker KE, Garbow JR, et al. CXCR4 regulates growth of both primary and metastatic breast cancer. Cancer Res 2004; 64: 8604-12.

[78] Luker KE, Luker GD. Functions of CXCL12 and CXCR4 in breast cancer. Cancer Lett 2006; 238: 30-41.

[79] Hall JM, Korach KS. Stromal cell-derived factor 1, a novel target of estrogen receptor action, mediates the mitogenic effects of estradiol in ovarian and breast cancer cells Mol Endocrinol 2003; 17: 792-803.

[80] Woerner BM, Warrington NM, Kung AL, Perry A, Rubin JB. Widespread CXCR4 activation in astrocytomas revealed by phospho-CXCR4-specific antibodies. Cancer Res 2005; 65: 113929.

[81] Scotton CJ, Wilson JL, Milliken D, Stamp G, Balkwill FR. Epithelial cancer cell migration: a role for chemokine receptors? Cancer Res 2001; 61: 4961-5.

[82] Wang J, Loberg R, Taichman RS. The pivotal role of CXCL12 (SDF-1)/CXCR4 axis in bone metastasis. Cancer Metastasis Rev 2006; $25: 573-87$.

[83] Takeuchi H, Fujimoto A, Tanaka M, Yamano T, Hsueh E, Hoon DS. CCL21 chemokine regulates chemokine receptor CCR7 
bearing malignant melanoma cells. Clin Cancer Res 2004; 10: 2351-8.

[84] Wiley HE, Gonzalez EB, Maki W, Wu MT, Hwang ST. Expression of $\mathrm{CC}$ chemokine receptor-7 and regional lymph node metastasis of B16 murine melanoma. J Natl Cancer Inst 2001; 93: 1638-43.

[85] Liotta LA. An attractive force in metastasis. Nature 2001; 410: 245.

[86] Burger M, Glodek A, Hartmann T, Schmitt-Graff A, Silberstein LE, Fujii N, Kipps TJ, Burger JA. Functional expression of CXCR4 (CD184) on small-cell lung cancer cells mediates migration, integrin activation, and adhesion to stromal cells. Oncogene 2003; 22: 8093-101.

[87] Arya M, Patel HR, McGurk C, et al. The importance of the CXCL12-CXCR4 chemokine ligand-receptor interaction in prostate cancer metastasis. J Exp Ther Oncol 2004; 4: 291-303.

[88] Zlotnik A. Involvement of chemokine receptors in organ-specific metastasis. Contrib Microbiol 2006; 13: 191-9.

[89] Geminder H, Sagi-Assif O, Goldberg L, et al. A possible role for CXCR4 and its ligand, the CXC chemokine stromal cell-derived factor-1, in the development of bone marrow metastases in neuroblastoma. J Immunol 2001; 167: 4747-57.

[90] Scala S, Giuliano P, Ascierto PA, et al. Human melanoma metastases express functional CXCR4. Clin Cancer Res 2006; 12: 2427-33.

[91] Zeelenberg IS, Ruuls-Van Stalle L, Roos E. The chemokine receptor CXCR4 is required for outgrowth of colon carcinoma micrometastases. Cancer Res 2003; 63: 3833-9.

[92] Scotton CJ, Wilson JL, Scott K, et al. Multiple actions of the chemokine CXCL12 on epithelial tumor cells in human ovarian cancer. Cancer Res 2002; 62: 5930-8.

[93] Wang LH, Liu Q, Xu B, et al. Identification of nuclear localization sequence of CXCR4 in renal cell carcinoma by constructing expression plasmids of different deletants. Plasmid 2009.

[94] Uchida D, Onoue T, Tomizuka Y, et al. Involvement of an autocrine stromal cell derived factor-1/CXCR4 system on the distant metastasis of human oral squamous cell carcinoma. Mol Cancer Res 2007; 5: 685-94.

[95] Bachelder RE, Wendt MA, Mercurio AM. Vascular endothelial growth factor promotes breast carcinoma invasion in an autocrine manner by regulating the chemokine receptor CXCR4. Cancer Res 2002; 62: 7203-6.

[96] Kato M, Kitayama J, Kazama S, Nagawa H. Expression pattern of CXC chemokine receptor-4 is correlated with lymph node metastasis in human invasive ductal carcinoma. Breast Cancer Res 2003; 5: R144-50.

[97] Phillips RJ, Burdick MD, Lutz M, Belperio JA, Keane MP, Strieter RM. The stromal derived factor-1/CXCL12-CXC chemokine receptor 4 biological axis in non-small cell lung cancer metastases. Am J Respir Crit Care Med 2003; 167: 1676-86.

[98] Hassan S, Baccarelli A, Salvucci O, Basik M. Plasma stromal cellderived factor-1: host derived marker predictive of distant metastasis in breast cancer. Clin Cancer Res 2008; 14: 446-54.

[99] Mirisola V, Zuccarino A, Bachmeier BE, Sormani MP, Falter J, Nerlich A, Pfeffer U. CXCL12/SDF1 expression by breast cancers is an independent prognostic marker of disease-free and overall survival. Eur J Cancer 2009; 45: 2579-87.

[100] Zhou W, Jiang Z, Song X, et al. Promoter hypermethylationmediated down-regulation of CXCL12 in human astrocytoma. J Neurosci Res 2008; 86: 3002-10.

[101] Wendt MK, Johanesen PA, Kang-Decker N, Binion DG, Shah V, Dwinell MB. Silencing of epithelial CXCL12 expression by DNA hypermethylation promotes colonic carcinoma metastasis. Oncogene 2006; 25: 4986-97.

[102] Wendt MK, Drury LJ, Vongsa RA, Dwinell MB. Constitutive CXCL12 expression induces anoikis in colorectal carcinoma cells. Gastroenterology 2008; 135: 508-17.

[103] Haedo MR, Gerez J, Fuertes M, et al. Regulation of pituitary function by cytokines. Horm Res 2009; 72: 266-74.

[104] Cunningham ET, Jr., Wada E, Carter DB, Tracey DE, Battey JF, De Souza EB. In situ histochemical localization of type I interleukin-1 receptor messenger RNA in the central nervous system, pituitary, and adrenal gland of the mouse. J Neurosci 1992; 12: 1101-14.

[105] Schettini G, Florio T, Meucci O, et al. Interleukin-1-beta modulation of prolactin secretion from rat anterior pituitary cells: involvement of adenylate cyclase activity and calcium mobilization. Endocrinology 1990; 126: 1435-41.

[106] Schettini G, Florio T, Meucci O, Scala G, Landolfi E, Grimaldi M. Effect of interleukin 1 beta on transducing mechanisms in 235-1 clonal pituitary cells. Part I: Modulation of adenylate cyclase activity. Biochem Biophys Res Commun 1988; 155: 1089-96.

[107] Schettini G, Meucci O, Florio T, Scala G, Landolfi E, Grimaldi M. Effect of interleukin 1 beta on transducing mechanisms in 235-1 clonal pituitary cells. Part II: Modulation of calcium fluxes. Biochem Biophys Res Commun 1988; 155: 1097-104.

[108] Koenig JI, Snow K, Clark BD, et al. Intrinsic pituitary interleukin-1 beta is induced by bacterial lipopolysaccharide. Endocrinology 1990; 126: 3053-8.

[109] Hanisch A, Dieterich KD, Dietzmann K, et al. Expression of members of the interleukin-6 family of cytokines and their receptors in human pituitary and pituitary adenomas. J Clin Endocrinol Metab 2000; 85: 4411-4.

[110] Spangelo BL, Macleod RM. The role of immunopeptides in the regulation of anterior pituitary hormone release. Trends Endocrinol Metab 1990; 1: 408-12.

[111] Renner U, Gloddek J, Arzt E, Inoue K, Stalla GK. Interleukin-6 is an autocrine growth factor for folliculostellate-like TtT/GF mouse pituitary tumor cells. Exp Clin Endocrinol Diabetes 1997; 105: 345-52.

[112] Pereda MP, Lohrer P, Kovalovsky D, et al. Interleukin-6 is inhibited by glucocorticoids and stimulates ACTH secretion and POMC expression in human corticotroph pituitary adenomas. Exp Clin Endocrinol Diabetes 2000; 108: 202-7.

[113] Spangelo BL, Judd AM, Isakson PC, MacLeod RM. Interleukin-6 stimulates anterior pituitary hormone release in vitro. Endocrinology 1989; 125: 575-7.

[114] Schettini G, Grimaldi M, Landolfi E, et al. Role of interleukin-6 in the neuroendocrine system. Acta Neurol (Napoli). 1991; 13: 361-7.

[115] Grimaldi M, Meucci O, Scorziello A, et al. Interleukin 6 modulation of second messenger systems in anterior pituitary cells. Life Sci 1992; 51: 1243-8.

[116] Arzt E, Buric R, Stelzer G, et al. Interleukin involvement in anterior pituitary cell growth regulation: effects of IL-2 and IL-6. Endocrinology 1993; 132: 459-67.

[117] Nagai Y, Watanabe K, Aso H, Ohwada S, Muneta Y, Yamaguchi T. Cellular localization of IL-18 and IL-18 receptor in pig anterior pituitary gland. Domest Anim Endocrinol 2006; 30: 144-54.

[118] Sakamoto Y, Koike K, Kiyama H, et al. Endotoxin activates a chemokinergic neuronal pathway in the hypothalamo-pituitary system. Endocrinology 1996; 137: 4503-6.

[119] Sawada T, Koike K, Kanda Y, et al. In vitro effects of CINC/gro, a member of the interleukin-8 family, on hormone secretion by rat anterior pituitary cells. Biochem Biophys Res Commun 1994; 202: 155-60.

[120] Tecimer T, Dlott J, Chuntharapai A, Martin AW, Peiper SC. Expression of the chemokine receptor CXCR2 in normal and neoplastic neuroendocrine cells. Arch Pathol Lab Med 2000; 124: 520-5.

[121] Koike K, Sakamoto Y, Sawada T, et al. The production of CINC/gro, a member of the interleukin-8 family, in rat anterior pituitary gland. Biochem Biophys Res Commun 1994; 202: 161-7.

[122] Zhang ZX, Koike K, Sakamoto Y, et al. Pituitary folliculo-stellatelike cell line produces a cytokine-induced neutrophil chemoattractant. Neuropeptides 1997; 31: 46-51.

[123] Licinio J, Wong ML, Gold PW. Neutrophil-activating peptide1/interleukin- 8 mRNA is localized in rat hypothalamus and hippocampus. Neuroreport 1992; 3: 753-6.

[124] Banisadr G, Dicou E, Berbar T, Rostene W, Lombet A, Haour F. Characterization and visualization of [125I] stromal cell-derived factor-1alpha binding to CXCR4 receptors in rat brain and human neuroblastoma cells. J Neuroimmunol 2000; 110: 151-60.

[125] Banisadr G, Fontanges P, Haour F, Kitabgi P, Rostene W, Melik Parsadaniantz S. Neuroanatomical distribution of CXCR4 in adult rat brain and its localization in cholinergic and dopaminergic neurons. Eur J Neurosci 2002; 16: 1661-71.

[126] Florio T, Casagrande S, Diana F, et al. Chemokine stromal cellderived factor lalpha induces proliferation and growth hormone release in $\mathrm{GH} 4 \mathrm{C} 1$ rat pituitary adenoma cell line through multiple intracellular signals. Mol Pharmacol 2006; 69: 539-46.

[127] Massa A, Casagrande S, Bajetto A, et al. SDF-1 controls pituitary cell proliferation through the activation of ERK1/2 and the Ca2+- 
dependent, cytosolic tyrosine kinase Pyk2. Ann N Y Acad Sci 2006; 1090: 385-98.

[128] Lee Y, Kim JM, Lee EJ. Functional expression of CXCR4 in somatotrophs: CXCL12 activates GH gene, GH production and secretion, and cellular proliferation. J Endocrinol 2008; 199: 191-9.

[129] Callewaere C, Banisadr G, Desarmenien MG, et al. The chemokine SDF-1/CXCL12 modulates the firing pattern of vasopressin neurons and counteracts induced vasopressin release through CXCR4. Proc Natl Acad Sci USA 2006; 103: 8221-6. Epub 2006.

[130] Barbieri F, Bajetto A, Stumm R, et al. Overexpression of stromal cell-derived factor 1 and its receptor CXCR4 induces autocrine/paracrine cell proliferation in human pituitary adenomas. Clin Cancer Res 2008; 14: 5022-32.

[131] Asa SL. Practical pituitary pathology: what does the pathologist need to know? Arch Pathol Lab Med 2008; 132: 1231-40.

[132] Green VL, Atkin SL, Speirs V, et al. Cytokine expression in human anterior pituitary adenomas. Clin Endocrinol (Oxf). 1996; 45: 17985.

[133] Suliman ME, Royds JA, Baxter L, Timperley WR, Cullen DR, Jones TH. IL-8 mRNA expression by in situ hybridisation in human pituitary adenomas. Eur J Endocrinol 1999; 140: 155-8.
[134] Lee YH, Noh TW, Lee MK, Larry Jameson J, Lee EJ. Absence of activating mutations of CXCR4 in pituitary tumours. Clin Endocrinol (Oxf) 2010; 72(2): 209-13.

[135] Nomura R, Yoshida D, Teramoto A. Stromal cell-derived factor-1 expression in pituitary adenoma tissues and upregulation in hypoxia. J Neurooncol 2009; 94: 173-81.

[136] Yoshida D, Nomura R, Teramoto A. Signaling Pathway Mediated by CXCR7, an Alternative Chemokine Receptor for Stromal-Cell Derived Factor-1alpha, in AtT20 mouse ACTH-secreting pituitary adenoma cells. J Neuroendocrinol 2009; 21: 481-8.

[137] Florio T, Barbieri F, Spaziante R, et al. Efficacy of a dopaminesomatostatin chimeric molecule, BIM-23A760, in the control of cell growth from primary cultures of human non-functioning pituitary adenomas: a multi-center study. Endocr Relat Cancer 2008; 15: 583-96.

[138] Yoshida D, Koketshu K, Nomura R, Teramoto A. The CXCR4 antagonist AMD3100 suppresses hypoxia-mediated growth hormone production in GH3 rat pituitary adenoma cells. J Neurooncol 2010.

(C) Barbieri et al.; Licensee Bentham Open.

This is an open access article licensed under the terms of the Creative Commons Attribution Non-Commercial License (http://creativecommons.org/licenses/by-nc/3.0/) which permits unrestricted, non-commercial use, distribution and reproduction in any medium, provided the work is properly cited. 